\title{
Jeugdgezondheidszorg: meer preventie voor weinig geld
}

\author{
S.P. Verloove-Vanhorick, ${ }^{12}$ S.A. Reijneveld ${ }^{13}$
}

"Het uniforme deel van het Basistakenpakket Jeugdgezondheidszorg (het deel dat aan alle kinderen in Nederland op dezelfde manier wordt aangeboden) bevatte voorheen een combinatie van 18 bewezen effectieve programmaonderdelen, te weten negen vaccinaties, zes screeningsprogramma's en drie vormen van preventieve advisering. Daarnaast werd een groot aantal programmaonderdelen aangeboden waarvan de werkzaamheid (nog) niet bewezen was. Van deze laatste werden een aantal alsnog onderzocht, om in een later stadium te kunnen besluiten over al dan niet handhaving in het uniforme Basistakenpakket JGZ. Sommige onderdelen lenen zich niet voor evaluatieonderzoek, maar worden door ouders of overheid dermate op prijs gesteld dat ze deel blijven uitmaken van het pakket. Mede dank zij dit gemengde aanbod is het bereik met gemiddeld rond $95 \%$ hoog in vergelijking met de ons omringende landen.

De afgelopen jaren is het Basistakenpakket JGZ uitgebreid, en is een aantal bestaande onderdelen wetenschappelijk beter onderbouwd. In dit artikel wordt de actuele stand van zaken per juni 2007 weergegeven, voortbouwend op een eerdere analyse uit $2003 .{ }^{1}$

\section{ACtuAlisatie}

Op grond van een advies van de Gezondheidsraad $^{2,3}$ en dus gebaseerd op de "stand van de wetenschap" is per 1 april 2006 de pneumokokkenvaccinatie toegevoegd aan het Rijksvaccinatieprogramma (RVP). De gezondheidswinst wordt geschat op het voorkomen van

\footnotetext{
TNO Kwaliteit van Leven, Leiden

2 Leids Universitair Medisch Centrum, WillemAlexander Kinder- en Jeugdcentrum, Leiden

3 Universitair Medisch Centrum Groningen, afdeling Sociale Geneeskunde
}

respectievelijk 78 sterfgevallen, 85 gevallen van hersenvliesontsteking, 308 gevallen van sepsis, 1800 gevallen van longontsteking en 52.000 gevallen van midden-oorontsteking. Tevens is per 1 januari 2007 de hielprikbloedscreening bij pasgeborenen uitgebreid met nog 13 zeldzame aangeboren stofwisselingsstoornissenen (noot a) en sikkelcelanemie, naast de bestaande screening op PKU-CHT-AGS. Hierdoor zullen jaarlijks gemiddeld 177 kinderen (88 wegens PKU-CHT-AGS, 89 wegens de 14 nieuwe aandoeningen) tijdig onderkend worden, en daardoor niet overlijden of gehandicapt raken. ${ }^{4}$

In de afgelopen jaren is bovendien een aantal bestaande onderdelen van het Basistakenpakket Jeugdgezondheid nader beschouwd. Op grond van de uitkomsten van bestaand en nieuw onderzoek worden nu als effectief beoordeeld: - screening op (aangeboren) niet-ingedaalde testis ${ }^{5}$

- advisering over passief roken ${ }^{6}$

- advisering over fluoride ${ }^{7}$

- advisering over zindelijkheid $^{8}$

Deze laatste advies-programma's en de reeds bewezen effectieve advisering over rugligging als slaaphouding ter preventie van wiegendood, over vitamine $\mathrm{K}$ ter preventie van bloedingen en over vitamine $D$ ter preventie van rachitis zullen in 2007 of 2008 hopelijk ook formeel deel worden van het uniforme Basistakenpakket. Het voormalige Platform JGZ adviseerde het Ministerie van VWS al eind 2005 deze adviesprogramma's over te hevelen van het maatwerkdeel naar het uniforme deel van het Basistakenpakket. ${ }^{9}$

In 2007 bevat het uniforme Basistakenpakket JGZ aldus 38 bewezen effectieve preventieprogramma's (tabel 1).

\section{KOSTEN}

De kosten van het totale programma JGZ zijn globaal toegenomen tot 433 miljoen euro (noot b). Als we deze kosten volledig toerekenen aan de 38 bewezen effectieve programma onderdelen (alle nog niet bewezen effectieve onderdelen worden in die berekening "gratis" geleverd) blijkt het totale programma zeer doelmatig: elk van de 38 programmaonderdelen kost slechts 11,4 miljoen euro (een daling ten opzichte van de schatting 2003: 21,1 miljoen euro). Bij een bereik van 95\% (anno 2007 zijn er 3,8 miljoen kinderen van 0-19 jaar in Nederland) komt het Basistakenpakket JGZ ten goede aan 3,6 miljoen kinderen. Per kind kost het totale preventieprogramma JGZ dus 120 euro per jaar, ofwel 3 euro per kind per programmaonderdeel per jaar (tabel 2). Dit is in lijn met een berekening uit 2006, die uitkwam op ongeveer 100 euro per inwoner van 0-19 jaar $^{12}$ en met gegevens uit de "Evaluatie JGZ 2006" (noot c).

De werkelijke situatie is nog gunstiger. Bij alle voorgaande berekeningen zijn alleen de individuele onderdelen van het Basistakenpakket JGZ betrokken. Daarnaast vindt een aantal "doelgroep/ populatiegerichte" activiteiten plaats, die deels ook bewezen effectief zijn: bevorderen van niet-beginnen-met-roken, "actie Tegengif", ${ }^{14}$ bevorderen van veilig vrijen, ${ }^{15}$ anti-pestprogramma's op scholen. ${ }^{16}$ Bovendien is binnen afzienbare tijd wetenschappelijke onderbouwing te verwachten van nog een aantal bestaande programmaonderdelen. Vele van deze activiteiten zullen dan alsnog "evidence based" blijken te zijn, of worden vervangen door bewezen effectieve programma's (tabel 3). ${ }^{17}$ Anno 2010 zou het uniforme basistakenpakket JGZ dan meer dan 50 bewezen effectieve onderdelen kunnen blijken te bevatten, tegen geschatte kosten van rond 500 miljoen 
Tabel 138 bewezen effectieve onderdelen van het Uniforme Basistakenpakket Jeugdgezondheidszorg per 2007

vaccinaties (11) difterie, tetanus, kinkhoest, polio, haemophilus influenzae type b, bof, maze-

(RijksVaccinatie Programma,RVP) len, rubella, meningokok C, pneumokok, hepatitis B (post-expositie profylaxe

en risicogroepen)

Screeningsprogramma (21) congenitale hypothyreoïdie, adrenogenitaal syndroom, phenylketonurie, 13

andere aangeboren stofwisselingsstoornissen, sikkelcelanemie (hielprik)

aangeboren perceptieve gehoorstoornis (neonatale gehoorscreening)

aangeboren ontwikkelingsstoornis heupen

aangeboren hartafwijking

(aangeboren) niet-ingedaalde testis

Adviezen (6)

vitamine $K$, vitamine $D$, preventie van passief roken, fluoride-tandpasta, slaaphouding rugligging, zindelijkheid

Tabel 2 Doelmatigheid Basistakenpakket JGZ 2007

\begin{tabular}{ll}
\hline effectieve programmaonderdelen & 38 \\
bereik 95\% van 3,8 miljoen kinderen 0-19 jaar & 3,6 miljoen kinderen \\
kosten & 433 miljoen euro \\
kosten per programmaonderdeel per jaar & 11,4 miljoen euro \\
kosten per kind per jaar & 120 euro \\
kosten per kind per programmaonderdeel per jaar & 3,17 euro \\
kosten per kind gedurende 20 jaar & 2400 euro \\
kosten per kind per programma-onderdeel & 63 euro
\end{tabular}

euro. Elk programma-onderdeel zou dan slechts 10 miljoen euro per jaar kosten. Zelfs als de "ontgroening" verder zou doorzetten, zodat er nog maar 3,5 miljoen kinderen van 0-19 jaar zouden zijn, betekent dat bij een bereik van 95\% (3,1 miljoen kinderen) kosten per kind per jaar 161 euro, en per kind per programmaonderdeel per jaar 3 euro. Doelmatiger besteding van collectieve middelen is nauwelijks denkbaar gezien de gezondheidswinst die daarmee bereikt wordt.

Ook de huidige kosten-effectiviteit van de jeugdgezondheidszorg is volgens de in de gezondheidszorg gehanteerde normen zeer gunstig. De gezondheidswinst komt ten goede aan kinderen en ouders, en de baten aan de curatieve gezondheidszorg, door een grote besparing op toekomstige kosten.

De jeugdgezondheidszorg wordt echter voor een groot deel bekostigd door gemeenten. Deze kijken soms meer naar uitgaven dan naar gezondheidswinst op lange termijn. Daardoor staat de jeugdgezondheidszorg de laatste jaren financieel sterk onder druk. Zo wordt gepropageerd de zorg te concentreren op "risicokinderen" en andere kinderen slechts op enkele momenten te onderzoeken. Niemand weet echter of de besparing die dit oplevert (en die kan worden gebruikt om de zorg voor risicokinderen te intensiveren)opweegt tegen het verlies van effectiviteit van het programma in de totale bevolking, waar gezond- heidsverlies door gemiste ziektegevallen onvermijdelijk zal zijn. Ook eventuele nadelige effecten zoals stigmatisering, verlies van de coördinerende rol in de zorg voor kinderen in brede zin zoals die toegekend is aan bijvoorbeeld het consultatiebureau in de Operatie Jong, en ontbreken van aandacht voor somatische stoornissen die frequent voorkomen bij complexe risicokinderen zijn niet bekend. Naar deze effecten is nader onderzoek nodig.

Tabel 3 Bestaande programma-onderdelen van het Uniforme Basistakenpakket JGZ waarnaar onderzoek gaande is dan wel hoge prioriteit heeft ${ }^{17}$ en waarvan omstreeks 2010 onderbouwing verwacht wordt.

\begin{tabular}{ll}
\hline screeningen & cystic fibrosis (hielprikscreening) \\
& gehoorverlies schoolleeftijd \\
& amblyopie (VOV-screening); visusstoornis (refractieafwijkingen) \\
& spraak- taalontwikkelingsstoornis \\
& scoliose, kyphose en hyperlordose \\
& hoofdomtrek zuigelingen \\
& psychosociale problemen (SDQ) \\
& dreigende kindermishandeling \\
& psychomotorische en sociale ontwikkeling(sachterstand) (Van Wiechen) \\
& groeistoornis (richtlijn groei) \\
& opvoedingsproblemen \\
& overgewicht \\
& pesten en geweld \\
& overgewicht \\
& borstvoeding \\
veiligheid (ongevallen in en om het huis) & opvoedingsondersteuning \\
advisering & voeding en bewegen \\
& huidproblemen \\
& pesten, geweld, wapens \\
& verslaving en genotmiddelen \\
& seksueel overdraagbare aandoeningen en anticonceptie
\end{tabular}




\section{TOEKOMST}

Het hoge bereik dat de JGZ heeft is mede te danken aan de medisch-somatische programmaonderdelen waar ouders vooral prijs op stellen. ${ }^{18}$ Dit hoge bereik, de laagdrempeligheid en de vanzelfsprekendheid waarmee ouders deelnemen aan het preventieprogramma JGZ maakt dat het een ideale infrastructuur biedt voor vroegsignalering van en tijdige hulpverlening bij problemen op ander gebied, zoals gedragsstoornissen, schooluitval, antisociale problematiek en beginnende criminaliteit.

Met de komst van het Electronisch Kind Dossier (2008 ?) en het daaraan gekoppelde kindvolgsysteem en de "verwijsindex" 19 waarmee ook signalen uit andere bronnen rond een kind, zoals de school, het bureau Jeugdzorg, de huisarts of de specialist, kunnen worden gebundeld (2010), zal een sluitend systeem van preventieve gezondheidszorg (somatisch, psychomotorisch en sociaal), vroegsignalering en tijdige hulpverlening bereikt kunnen worden, tegen relatief bescheiden kosten.

\section{NOTEN}

a De screening op tyrosinemie is inmiddels tijdelijk gestopt wegens te veel fout-positieven; hervatting wordt beoogd in oktober 2007.

b Schatting 2003: 380 miljoen euro, zijnde 309 miljoen euro ${ }^{2,10,11}$ plus geschatte verborgen kosten. Inflatie 3\% per jaar. Kosten 2007: 428 miljoen euro. Toevoeging pneumococcen vaccinatie: 5,90 euro per vaccinatie, d.w.z. $4 \times 200.000 \times € 5,90=4,7$ miljoen euro per jaar. Totaal 433 miljoen euro.

C Schatting $2005::^{13}$ bedrag per kind per gemeente, mediaan 2005: 0-4 jaar $€$ 212,41; 4-19 jaar: $€ 35,82$. Totaal 285 miljoen $€$ (exclusief verborgen kosten en maatwerk)

\section{LITERATUUR}

1. Verloove-Vanhorick SP, Verkerk PH, Leerdam FJM van, Reijneveld SA, Hirasing RA. Jeugdgezondheidszorg: veel preventie voor weinig geld. NTvG 2003;147:895-98

2. Gezondheidsraad. Algemene vaccinatie tegen meningokokken $C$ en pneumokokken. Publicatienr. 2001/27. Den Haag: Gezondheidsraad, 2001.

3. Gezondheidsraad. Vaccinatie van zuigelingen tegen pneumokokkeninfecties. Den Haag: Gezondheidsraad, 2005; publicatie nr. 2005/13.

4. Gezondheidsraad. Neonatale screening. Den Haag: Gezondheidsraad 2005; publicatie $\mathrm{nr}$ 2005/11.

5. Platform JGZ: Advies Basistakenpakket Jeugdgezondheidszorg 0-19 jaar. 7 oktober 2005. www.rivm.nl/jeugdgezondheid/ jgz/adviezen. Geraadpleegd 12 maart 2007

6. Snick HKA. Sterke daling van de orchidopexiefrequentie op Walcheren. Ned Tijdschr Geneesk 1988; 132: 777-80.

7. Crone M, Reijneveld SA, Willemsen MC, Hira Sing RA. Parental education about passive smoking in infabcy does work. Eur J Public Health 2003; 269-74.

8. Kalsbeek H. Het effect van cariëspreventieve maatregelen. In:Volksgezondheids Toekomst Verkenning 1997, deel IV Effecten van preventie. Gunning-Schepers LJ en Jansen J, eindredactie. RIVM, Bilthoven, 1997.

9. Leerdam, FJM van. Enuresis, a major problem or a simple developmental delay?Proefschrift, Vrije Universiteit Amsterdam, 2005, ISBN: 90-5669-000-0

10. Kosten Basispakket Jeugdgezondheidszorg. Woerden: Van Naem \& Partners / PriceWaterhouseCoopers, 2002.

11. Rutz SI, Overbey RI, Witte KE, Jansen J, Oers JAM van. Brancherapport Preventie, '98-'01. Centrum voor Volksgezondheid Toekomst Verkenning. Bilthoven: Rijksinstituut voor Volksgezondheid en Milieu, 2002.

12. Bekker-Grob EW de, Polder JJ, Witte KE, Mackenbach JP, Meerding WJ. Kosten van preventie in Nederland 2003; zorg voor euro's-4. ErasmusMC en RIVM, Bilthoven, 2006. RIVM rapportnummer:270751011; ISBN-10:90-6960-143-5 en ISBN-13: $978-$ 90-6960-143-4.

13. TNO Kwaliteit van Leven en Van Naem \& partners. Evaluatie JGZ 2006. Leiden, 3 november 2006, rapport in opdracht van Ministerie VWS.

14. Crone MR, Reijneveld SA, Willemsen MC, Leerdam FJ van, Spruijt RD, Sing RA. Prevention of smoking in adolescents with lower education: a school based intervention study.J Epidemiol Community Health. 2003 Sep;57(9):675-80.

15. Wiefferink $\mathrm{CH}$, Poelman J, Linthorst $\mathrm{M}$, Vanwesenbeeck I, van Wijngaarden JC, Paulussen TG. Outcomes of a systematically designed strategy for the implementation of sex education in Dutch secondary schools. Health Educ Res. 2005 Jun; 20(3):323-33.

16. Fekkes M, Pijpers FIM, Verloove-Vanhorick SP. Effects of anti-bullying school program on bullying and health complaints. Arch Pediatr Adolesc Med 2006; 160:638-644.

17. GGD Nederland, Z-org, VUmc, TNO, ErasmusMc. Update Programmeringsstudie Effectonderzoek Jeugdgezondheidszorg 0-19 jaar. November 2005. ISBN-10: 9072779-40-1. ISBN-13: 978-90-72779-40-3.

18. Themarapport ouders jonge kinderen, Jeugdmonitor Zeeland, oktober 2005 www.jeugdmonitorzeeland.nl/publicaties/themarapporten ouders jonge kinderen. Geraadpleegd 12 maart 2007.

19. Ross-van Dorp C. Toespraak 11 oktober 2006. www.minvws.nl/toespraken/djb/ 2006/ross-presenteert-verwijsindex-aanwethouders-jeugd.asp. Geraadpleegd 12 maart 2007.

\section{CORRESPONDENTIEADRES \\ Mevrouw prof. dr. S.P. Verloove- Vanhorick, TNO Kwaliteit van Leven, Postbus 2215, 2301 CE Leiden, tel. 071-5181671, e-mail: pauline.verloove@tno.nl}

